\title{
Ingestion of marine debris by Wedge-tailed Shearwaters (Ardenna pacifica) on Lord Howe Island, Australia during 2005-2018
}

\author{
Jennifer L. Lavers ${ }^{1}$, Ian Hutton ${ }^{2}$, and Alexander L. Bond ${ }^{3}$ \\ ${ }^{1}$ Institute for Marine and Antarctic Studies, University of Tasmania, 20 Castray Esplanade, \\ Battery Point, Tasmania, 7004 Australia \\ ${ }^{2}$ Lord Howe Island Museum, P.O. Box 157, Lord Howe Island, New South Wales, 2898 \\ Australia \\ ${ }^{3}$ Bird Group, Department of Life Sciences, The Natural History Museum, Akeman Street, \\ Tring, Hertfordshire, United Kingdom HP23 6AP \\ *Corresponding author. E-mail address: Jennifer.Lavers@utas.edu.au (J.L. Lavers)
}

\begin{abstract}
Annual rates of plastic production have been increasing rapidly since the 1950s. Inadequate or improper disposal of plastic products has contributed to a significant increase in plastic debris in the world's oceans and a corresponding increase in the number of species negatively affected by this debris. Here we investigate trends in the type, amount, and colour of ingested plastic over time, and determine whether ingested plastic contributes to reduced health of Wedge-tailed Shearwaters (Ardenna pacifica) on Lord Howe Island, Australia. The results show no clear influence of ingested plastic on body condition, while trends in the prevalence, number, and mass of plastic items ingested per bird during 2005 and 2013-2018 were more variable. There was some evidence adult birds are selecting plastic by colour. Future monitoring of this pan-tropical seabird would provide a unique opportunity to gather data from multiple sites, concurrently.
\end{abstract}

Keywords: Long-term trends; Plastic ingestion; Plastic pollution; Tasman Sea; Wedge-tailed Shearwater

\section{Introduction}

First known as Bakelite, plastic was invented in 1907 (Baekeland, 1909), mass production began in the 1950s, increasing exponentially, and now reaches 335 million metric tonnes per year (PlasticsEurope, 2018). Plastics are designed to be light-weight, convenient, and durable, several characteristics that make them suitable packaging alternatives compared to other materials such as glass or metal, but also makes them problematic in the environment (Hopewell et al., 2009). Plastics are inexpensive to produce and widely consumed (UNEP, 2014). In Australia, 37\% of plastic items comprise single-use packaging, leading to a significant increase in disposal rates in the last half century (PACIA, 2013).

Once in the ocean, plastic particles can both sink and float, becoming dispersed over long distances via tides and currents (Thiel et al., 2013). Significant quantities of plastic are now in all oceanic basins (Eriksen et al., 2014) and freshwater systems (Eerkes-Medrano et al., 2015), accounting for $>80 \%$ of debris items recorded at-sea, on beaches, and along river banks (Gregory and Ryan, 1997; Hammer et al., 2012). These synthetic materials persist for decades in the marine environment, posing a considerable threat to a diverse array of marine flora and fauna (Gall and Thompson, 2015).

In Australia, at least 77 marine species are known to be impacted by plastic debris, with Australian fur seals (Arctocephalus pusillus doriferus) and Flesh-footed Shearwaters (Ardenna carneipes) exhibiting some of the highest rates of entanglement and ingestion in the world, respectively (Ceccarelli, 2009; Lavers and Bond, 2016b; Lavers et al., 2014). Worryingly, entanglement and ingestion rates in both Australian pinnipeds and shearwaters 
are increasing (Lavers et al., in prep; Page et al., 2004) despite plastic debris being identified as a key threatening process in Australian legislation (DEWHA, 2014; Parliament of Australia, 2016) and the release of plastic into the marine environment prohibited under international law (MARPOL Annex V resolution MEPC.201(62)), to which Australia is a signatory. Under the Convention on Biological Diversity 1992, signatories (including Australia) have pledged to achieve the Aichi Biodiversity Targets, including that "by 2020, pollution has been brought to levels that are not detrimental to ecosystem function and biodiversity."

Interactions between wildlife and plastic debris can contribute directly to mortality through entanglement, or starvation and dehydration resulting from blockages, and damage to the digestive tract due to the ingestion of plastic (Gall and Thompson, 2015). The indirect, sub-lethal effects resulting from plastic debris are less well understood, but include exposure to toxins adhered to the surface of ingested plastic fragments (Lavers and Bond, 2016a; Lavers et al., 2014; Tanaka et al., 2015). The ingestion of significant quantities of plastic is also correlated with and contributes to reduced body condition (morbidity), with fledgling Flesh-footed Shearwaters exhibiting reduced wing length and body mass thought to reduced their survival by around 10\% (Lavers et al., 2014).

Wedge-tailed Shearwaters (Ardenna pacifica) have been reported to ingest plastic in Australia (Hutton et al., 2008; Verlis et al., 2013) and elsewhere (Fry et al., 1987; Rapp et al., 2017), but the extent to which this may affect the health of individuals has not been investigated. Our goal was therefore to assess changes in the frequency of plastic ingestion by Wedge-tailed Shearwaters from eastern Australia collected during 2005 and 2013-2018, and to examine the relationship between plastic load and fledgling body condition.

\section{Methods}

\subsection{Sampling birds}

Wedge-tailed Shearwater fledglings (approximately 80 days old) were sampled on Lord Howe Island $\left(31^{\prime} 31^{\circ} \mathrm{S}, 159^{\prime} 02^{\circ} \mathrm{E}\right)$, New South Wales, including an adjacent islet, from late-April until mid-May 2005 and 2013-2018 (Fig. 1). Fledglings of this species do not typically regurgitate a bolus and receive their final meal approximately two weeks before departing the nest (Baduini, 2002; Hutton et al., 2008). As such, it's unlikely that new plastic items would be accumulated by young birds during or after the sampling period.

Body mass $( \pm 10 \mathrm{~g})$ was determined using a spring balance, wing chord (flattened; \pm 1 $\mathrm{mm}$; to the tip of the longest primary feather) using a stopped ruler, and head+bill and culmen length using Vernier callipers $( \pm 0.1 \mathrm{~mm})$. Ingested plastic was collected by stomach flushing following procedures outlined by Duffy and Jackson (1986). In brief, seawater (approximately $90 \mathrm{ml}$ ) at ambient temperature was gently pumped into the proventriculus through a tube, thus displacing any food or plastic items. Once fluid and stomach contents began to flow back up the throat (i.e., once the stomach was completely filled), the bird was inverted over a container to collect anything expelled. Freshly dead ( $<24$ hours) fledgling shearwater carcasses were collected from beaches adjacent to the colonies after unsuccessful fledging attempts (often a result of strong onshore winds) each morning. Birds were measured, weighed, and necropsied immediately upon collection.

Plastic items from each individual bird were dried and weighed separately to the nearest $0.001 \mathrm{~g}$ using an electronic balance and sorted by colour (white, blue, green, red/pink, yellow/orange, and black/grey/brown) and type following van Franeker and Law (2015) and Provencher et al. (2017): industrial pellets (nurdles) and user plastic (all non-industrial remains of plastic objects) differentiated into five subcategories including sheet-like plastics (e.g., bag and film), thread-like plastics (e.g., rope and line), foam (e.g., polystyrene), fragments (unidentifiable hard plastics), and other (e.g., balloon rubber, melted plastic). 


\subsection{Statistical methods}

We first examined whether the prevalence, number of pieces, or mass of plastic varied among years using generalized linear models with binomial, Poisson, and normal error structures, respectively. We report the mean \pm SD and range following Provencher et al. (2017). To test whether the mass of ingested plastic was related to individuals' body size, we used a general linear models and examined the relationship between ingested plastic mass, and birds' mass, culmen length, head+bill length, and wing chord length. We also compared the body mass of birds among years and between the two sampling methods (lavage of live birds, and necropsy of beach-washed dead birds) using general linear models.

We compared the composition of ingested plastics (in terms of colour and plastic type) among years using Jaccard's index of similarity, where values of $\mathrm{J}=0$ indicate complete dissimilarity, and $\mathrm{J}=1$ indicates identical composition; Values of $\mathrm{J}>0.60$ were considered to be significant overlap. Lastly, we conducted a power analysis to assess the sample size needed to detect a change (5\%-100\%; in 5\% increments; with power of $80 \%)$ in the frequency of plastic ingestion by Wedge-tailed Shearwater fledglings over time, as described in van Franeker and Meijboom (2002). All statistical analyses were done in R 3.4.3 (R Core Team, 2018) using the packages lme4 (Bates et al., 2015) and vegan (Oksanen et al., 2013); results from parametric tests were considered statistically significant when $p<0.05$.

\section{Results}

We examined 224 Wedge-tailed Shearwater fledglings for plastic debris (lavage: $\mathrm{n}=$ 154; necropsy: $\mathrm{n}=70$ ) during 2005 and 2013-2018 (Table 1). Overall, $35.2 \%$ of fledglings sampled during 2013-2018 contained $1.07 \pm 3.21$ pieces of plastic weighing $0.086 \pm 0.256 \mathrm{~g}$ (Table 1) compared to $46 \%$ of lavaged birds sampled in $2005(\mathrm{n}=30)$. The frequency of occurrence of plastic was $31.2 \%$ for lavaged birds, and $44.3 \%$ for necropsied birds, the mean number of pieces was $1.01 \pm 3.68$ and $1.04 \pm 1.76$, respectively, and the mass of ingested plastic was slightly higher in necropsied birds where the gizzard could also be examined (lavage: $0.069 \pm 0.235 \mathrm{~g}$, necropsy: $0.107 \pm 0.281 \mathrm{~g}$ ).

While most items ingested were white $(72.4 \%, \mathrm{n}=173$; Table 2$)$, the composition of colours differed among years, with the exception of 2005, 2014, 2015, and 2018, where the overlap was significant (Table 3). Notably 2013 differed from all other years in colour composition (all $\mathrm{J}<0.45$; Table 3 ). The type of plastic ingested was similar in most years, though 2013 was most dissimilar from the rest (Table 4), which reflected an increase in the proportion of user fragments (2013: 63\%, 2018: 97\%; Table 5) and a general decrease in the proportion of industrial pellets $(2013: 36 \%, 2017: 3 \%)$. The provenance of most items could not be determined, however bottle caps $(\mathrm{n}=3,2.0 \%)$, oyster spacers (from the aquaculture industry; $n=2,1.3 \%)$, and balloon fragments $(n=3,2.0 \% ;$ Fig. 2$)$ were identified in some birds.

The prevalence of plastic in lavaged Wedge-tailed Shearwaters was unchanged from $2005-2018(\mathrm{z}=-1.18, p=0.24)$, though the number of pieces per individual decreased significantly $(\mathrm{z}=-7.13, p<0.001)$, as did the mass of plastic $\left(\mathrm{F}_{1,150}=11.71, p<0.001 ; \beta=-\right.$ $0.014)$. Among necropsied birds, there was a significant increase in the prevalence of plastic $(\mathrm{z}=3.03, p=0.002, \beta=0.414)$, a significant increase in the number of pieces $(\mathrm{z}=3.16, p=$ $0.002, \beta=0.204)$, and no change in plastic mass $\left(\mathrm{F}_{1,69}=1.29, p=0.26\right)$.

Lavaged birds weighed significantly more than necropsied birds $\left(\mathrm{F}_{1,214}=87.82, \mathrm{p}<\right.$ $0.001)$, and mass differed significantly among years $\left(\mathrm{F}_{1,214}=25.97, p<0.001\right)$; the sample type $\times$ year interaction was not significant $\left(\mathrm{F}_{1,214}=1.70, p=0.19\right)$. There was no relationship between the mass of ingested plastic and birds' mass (lavage: $\mathrm{F}_{1,149}=1.06, p=0.30$; necropsy: $\mathrm{F}_{1,64}=0.08, p=0.78$ ), head+bill length (lavage: $\mathrm{F}_{1,75}=0.26, p=0.61$; necropsy: 
$\mathrm{F}_{1,54}=0.21, p=0.65$ ), culmen length (lavage: $\mathrm{F}_{1,105}=0.11, p=0.74$; necropsy: $\mathrm{F}_{1,67}=1.40, p$ $=0.24$ ), or wing chord length (lavage: $\mathrm{F}_{1,76}=0.22, p=0.64$; necropsy: $\mathrm{F}_{1,57}=0.33, p=0.57$ ).

Based on the mean sample size on Lord Howe Island during 2013-2018 (32 \pm 13

birds; Table 1), results of the power analysis indicate only a $35 \%$ change in the frequency of occurrence of ingested plastic could be detected.

\section{Discussion}

The results of our study indicate the proportion of Wedge-tailed Shearwater fledglings on Lord Howe Island being fed plastic debris by their parent birds remained relatively constant during 2005-2016, with prevalence and counts potentially increasing in recent years, especially in necropsied birds (Table 1). Overall, the prevalence data for Lord Howe Island are comparable with Heron Island ( 1,000 km north-west of Lord Howe Island) where around $20 \%$ of fledglings sampled in 2012 contained plastic (Verlis et al., 2013). While the proportion of Wedge-tailed Shearwater fledglings containing plastic appears to be higher in birds from Kaua'i, Hawai'i than Australia (Table 1), the mass of plastic consumed per bird is comparable. There is a higher density of plastic debris in the North Pacific Ocean than the Tasman Sea (Howell et al., 2012; Rudduck et al., 2017), but the small sample sizes found in any given year (Table 1) make it difficult to draw conclusions applicable to the species as a whole.

The majority of ingested plastic items recovered from Wedge-tailed Shearwater fledglings on Lord Howe Island were white (69\% overall), however the colours fed to chicks by the adult birds varied among years (Table 2). The colour of plastic items consumed appears to be relatively consistent geographically, with Wedge-tailed Shearwater fledglings from Kaua'i and Heron Island also being fed mostly white plastics (77-83\%; Table 2; Kain et al., 2016; Verlis et al., 2013). This corresponds with the distribution of plastic colours at sea, with white and blue being the most commonly reported (Shaw and Day, 1994). Plastic colour selection in seabirds may be influenced by additional factors, including the degree of similarity to potential prey items (Derraik, 2002; Ryan, 1987). For example, Verlis et al. (2013) suggest Wedge-tailed Shearwaters on Heron Island select white and black plastic due to their resemblance to squid and pumice, respectively. Flesh-footed Shearwaters on Lord Howe Island consume considerable quantities of squid and pumice, and blue and white plastics are most common (accounting for $80 \%$ of ingested items; Lavers et al., 2014). The availability of different plastic colours at sea may also influence the colour of items ingested by seabirds. Light-coloured plastics dominate in the marine environment (Moser and Lee, 2012; Shaw and Day, 1994), including waters off eastern Australia (Reisser et al., 2013; Rudduck et al., 2017) where Australian Wedge-tailed Shearwaters forage (McDuie et al., 2015; Miller et al., 2018). Flesh-footed Shearwaters from Lord Howe Island exhibit strong selection for plastic colour while birds from Western Australia appear to choose colours based on what is available in waters adjacent to the breeding colony (Lavers and Bond, 2016b); it is possible Wedge-tailed Shearwaters on Lord Howe may also be actively selecting white plastics (Table 2).

There was a high degree of similarity among the types of ingested plastic items among years (Table 4). While industrial pellets were absent in 2005, the proportion consumed by Wedge-tailed Shearwaters decreased during 2013-2017. A similar pattern has also been reported for Flesh-footed Shearwaters on Lord Howe Island (Lavers et al., in prep) and various seabirds in the South Atlantic, North Pacific, and Indian Oceans (Ryan, 2008; van Franeker et al., 2011; Vlietstra and Parga, 2002). This reduction has been largely attributed to industry efforts to reduce the loss of pellets for economic reasons (e.g., Operation Clean Sweep; OCS, 2015). 
Few studies have highlighted a range of non-lethal consequences as a result of the ingestion of plastic by seabirds, including exposure to chemical pollutants (Lavers and Bond, 2016a; Tanaka et al., 2015). Reductions in seabird body condition, such as lower body mass and shorter wing lengths, have been attributed to the ingestion of plastic (Auman et al., 1998; Lavers et al., 2014). The relatively low levels of plastic ingestion by Wedge-tailed Shearwaters does not appear to significantly impact the physical health of fledglings on Lord Howe Island, or Heron Island (Verlis et al., 2013). This contrasts sharply with the Fleshfooted Shearwater, which breeds and forages in the same locations as the Wedge-tailed Shearwater (Reid, 2010), yet suffers from much higher rates of plastic ingestion and a range of sub-lethal effects (Lavers et al., 2014). However, it is important to note that information on the chemical body burden in Wedge-tailed Shearwaters in relation to plastic ingestion is lacking, particularly in relation to the toxicological effects of plastics at the nano-scale (Koelmans et al., 2015; Mattsson et al., 2015).

The prevalence of ingested plastic in some species appears to be increasing over time (Lavers and Bond, 2016a; Robards et al., 1995), highlighting a need for ongoing monitoring, though obtaining sufficient sample sizes to detect meaningful trends can be difficult for some species (Lavers and Bond, 2016a; Ryan, 2016). Furthermore, the temporal and geographic variation in the type, colour, or amount of plastic recorded within single species poses a challenge when interpreting individual studies. Quantifying changes in the composition of plastics in the ocean, as indicated by seabirds, requires a coordinated effort following a standardised sampling protocol such as that proposed by Provencher et al. (2017). Marine organisms like the Northern Fulmar (Fulmarus glacialis) can act as indicators of marine litter levels in their environment in a way that is virtually impossible to replicate by direct physical measurements (i.e., high cost and logistical challenges of trawling for plastics at-sea; Ryan et al., 2009). With breeding sites across the tropical Indian and Pacific oceans (Marchant and Higgins, 1990; Whittow, 1997), the Wedge-tailed Shearwater provides a unique opportunity to gather data from multiple sites concurrently with minimal disruption to relatively large and robust populations. Monitoring plastic pollution on an international scale is likely only possible with the use of indicators such as seabirds. If done consistently, it has the potential to provide policy makers with a robust framework for making management decisions aimed at improving the quality of the marine environment and achieving global biodiversity conservation and sustainability targets.

\section{Acknowledgements}

Special thanks to BirdLife Tasmania, Detached Foundation, Sydney SeaLife Foundation, Trading Consultants Ltd (V. Wellington), L. Brice, C. Noone, and the W.V. Scott Charitable Trust for providing funding for this project. Samples were collected under the approval of the University of Tasmania Animal Ethics Committee (permit no. A13836 and A15980).

Assistance in the field was provided by numerous dedicated volunteers, particularly the Lord Howe Island Board and local community, Two Hands Project (S. Stuckenbrock \& P. Sharp), P. Clive, A. Fidler, P. Lewis, B. Looker, A. Lombal, T. Potts, P. Puskic, K. Richards, J. \& C. Shick, K. \& W. Savage, and C. \& C. Watts. Comments from two anonymous reviewers improved earlier drafts.

\section{References}

Auman, H.J., Ludwig, J.P., Giesy, J.P., Colborn, T., 1998. Plastic ingestion by Laysan Albatross chicks on Sand Island, Midway Atoll, in 1994 and 1995, in: Robertson, C.J.R., Gales, R. (Eds.). Surrey Beaty \& Sons, Chipping Norton, pp. 239-244.

Baduini, C.L., 2002. Parental provisioning patterns of Wedge-tailed Shearwaters and their relation to chick body condition. Condor 104, 823-831. 
Baekeland, L.H., 1909. The synthesis, constitution, and uses of bakelite. J Ind. Eng. Chem. 1, 149-161.

Bates, D., Maechler, M., Bolker, B., Walker, S., 2015. Fitting linear mixed-effects models using lme4. J. Stat. Softw. 67, 1-48.

Ceccarelli, D.M., 2009. Impacts of plastic debris on Australian marine wildlife. Report by C\&R Consulting for the Department of the Environment, Water, Heritage and the Arts, Canberra.

Derraik, J.G.B., 2002. The pollution of the marine environment by plastic debris: a review. Mar. Pollut. Bull. 44, 842-852.

DEWHA, 2014. Threat Abatement Plan for the impacts of marine debris on vertebrate marine life: review 2009-2014. Department of the Environment, Water, Heritage and the Arts, Canberra.

Eerkes-Medrano, D., Thompson, R.C., Aldridge, D.C., 2015. Microplastics in freshwater systems: A review of the emerging threats, identification of knowledge gaps and prioritisation of research needs. Water Res. 75, 63-82.

Eriksen, M., Lebreton, L.C.M., Carson, H.S., Thiel, M., Moore, C.J., Borerro, J.C., Galgani, F., Ryan, P.G., Reisser, J., 2014. Plastic pollution in the world's oceans: more than 5 trillion plastic pieces weighing over 250,000 tons afloat at sea. PLoS One 9, e111913.

Fry, D.M., Fefer, S.I., Sileo, L., 1987. Ingestion of plastic debris by Laysan Albatrosses and Wedge-tailed Shearwaters in the Hawaiian Islands. Mar. Pollut. Bull. 18, 339-343.

Gall, S.C., Thompson, R.C., 2015. The impact of debris on marine life. Mar. Pollut. Bull. 92, 170-179.

Gregory, M.R., Ryan, P.G., 1997. Pelagic plastics and other seaborne persistent synthetic debris: a review of southern hemisphere perspectives. Springer-Verlag, New York.

Hammer, J., Kraak, M.H.S., Parsons, J.R., 2012. Plastics in the marine environment: the dark side of a modern gift, in: Whitacre, D.M. (Ed.), Reviews of Environmental Contamination and Toxicology. Springer Science, pp. 1-44.

Harrison, C.S., Hida, T.S., Seki, M.P., 1983. Hawaiian seabird foraging ecology. Wildlife Monogr. 85, 1-71.

Hopewell, J., Dvorak, R., Kosior, E., 2009. Plastics recycling: challenges and opportunities. Philos. Trans. Royal Soc. B. 364, 2115-2126.

Howell, E.A., Bograd, S.J., Morishige, C., Seki, M.P., Polovina, J.J., 2012. On North Pacific circulation and associated marine debris concentration. Mar. Pollut. Bull. 65, 16-22.

Hutton, I., Carlile, N., Priddel, D., 2008. Plastic ingestion by Flesh-footed Shearwaters, Puffinus carneipes, and Wedge-tailed Shearwaters, Puffinus pacificus. Pap. Proc. R. Soc. Tas. 142, 67-72.

Kain, E., Lavers, J.L., Berg, C., Raine, A.F., Bond, A.L., 2016. Plastic ingestion by Newell's (Puffinus newelli) and Wedge-tailed Shearwaters (P. pacificus) in Hawaii. Environ. Sci.

Pollut. Res. 23, 23951-23958.

Koelmans, A.A., Besseling, E., Shim, W.J., 2015. Nanoplastics in the aquatic environment.

Critical review, in: Bergmann, M., Gutow, L., Klages, M. (Eds.), Marine Anthropogenic

Litter. Springer International Publishing, Cham, pp. 325-340.

Lavers, J.L., Bond, A.L., 2016a. Ingested plastic as a route for trace metals in Laysan Albatross (Phoebastria immutabilis) and Bonin Petrel (Pterodroma hypoleuca) from Midway Atoll. Mar. Pollut. Bull. 110, 493-500.

Lavers, J.L., Bond, A.L., 2016b. Selectivity of Flesh-footed Shearwaters for plastic colour: evidence for differential provisioning in adults and fledglings. Mar. Environ. Res. 113, 1-6. Lavers, J.L., Bond, A.L., Hutton, I., 2014. Plastic ingestion by Flesh-footed Shearwaters (Puffinus carneipes): Implications for chick body condition and the accumulation of plasticderived chemicals. Environ. Pollut. 187, 124-129. 
Lavers, J.L., Hutton, I., Bond, A.L., in prep. Trends in marine pollution: insights from a 17year investigation of Flesh-footed Shearwater (Ardenna carneipes) health and plastic ingestion rates.

Marchant, S., Higgins, P.J., 1990. Handbook of Australian, New Zealand, and Antarctic birds. Volume 1: ratites to ducks. Oxford University Press, Melbourne.

Mattsson, K., Hansson, L.A., Cedervall, T., 2015. Nano-plastics in the aquatic environment. Environmental Science: Processes \& Impacts 17, 1712-1721.

McDuie, F., Weeks, S.J., Miller, M.G.R., Congdon, B.C., 2015. Breeding tropical shearwaters use distant foraging sites when self-provisioning. Mar. Ornithol. 43, 123-129.

Miller, M.G.R., Carlile, N., Phillips, J.S., McDuie, F., Congdon, B.C., 2018. The importance of tropical tuna for seabird foraging over a marine productivity gradient. Mar. Ecol. Prog.

Ser. 586, 233-249.

OCS, 2015. Operation Clean Sweep program manual. Plastics Industry Trade Association, American Chemistry Council, Washington DC.

Oksanen, J., Blanchet, F.G., Kindt, R., Legendre, P., Minchin, P.R., O'Hara, R.B., Simpson, G.L., Solymos, P., Stevens, M.H.H., Wagner, H., 2013. Vegan: R functions for vegetation ecologists. R package version 2.0.

PACIA, 2013. National plastics recycling survey 2011-12: final report. Plastics and Chemicals Industries Association Carlton, Victoria, p. 62 pp.

Page, B., McKenzie, J., McIntosh, R., Baylis, A., Morrissey, A., Calvert, N., Haase, T., Berris, M., Dowie, D., Shaughnessy, P.D., Goldsworthy, S.D., 2004. Entanglement of Australian sea lions and New Zealand fur seals in lost fishing gear and other marine debris before and after Government and industry attempts to reduce the problem. Mar. Pollut. Bull. 49, 33-42.

Parliament of Australia, 2016. Toxic tide: the threat of marine plastic. Commonwealth of Australia, Environment and Communications References Committee, Canberra.

PlasticsEurope, 2018. Plastics - the facts 2018: an analysis of European plastics production, demand and waste data. PlasticsEurope Market Research Group, Brussels, Belgium.

Provencher, J.F., Bond, A.L., Avery-Gomm, S., Borrelle, S.B., Brave Rebolledo, E.L., Hammer, S., Kühn, S., Lavers, J.L., Mallory, M.L., Trevail, A.M., van Franeker, J.A., 2017. Quantifying ingested debris in marine megafauna: a review and recommendations for standardization. Anal. Methods 9, 1454-1469.

R Core Team, 2018. R: a language and environment for statistical computing. Version 3.4.3 [computer program]. R Foundation for Statistical Computing, Vienna, Austria.

Rapp, D.C., Youngren, S.M., Hartzell, P., Hyrenbach, D.K., 2017. Community-wide patterns of plastic ingestion in seabirds breeding at French Frigate Shoals, Northwestern Hawaiian Islands. Mar. Pollut. Bull.

Reid, T., 2010. Modelling the foraging ecology of the Flesh-footed Shearwater Puffinus carneipes in relation to fisheries and oceanography, $\mathrm{PhD}$ thesis, Quantitative Marine Science. University of Tasmania, Hobart.

Reisser, J., Shaw, J., Wilcox, C., Hardesty, B.D., Proietti, M., Thums, M., Pattiaratchi, C., 2013. Marine plastic pollution in waters around Australia: characteristics, concentrations, and pathways. PLoS One 8, e80466.

Robards, M.D., Piatt, J.F., Wohl, K.D., 1995. Increasing frequency of plastic particles ingested by seabirds in the subarctic North Pacific. Mar. Pollut. Bull. 30, 151-157.

Rudduck, O.-A., Lavers, J.L., Fischer, A.M., Stuckenbrock, S., Sharp, P.B., Banati, R.B., 2017. Inter-annual variation in the density of anthropogenic debris in the Tasman Sea. Mar. Pollut. Bull. 124, 51-55.

Ryan, P.G., 1987. The incidence and characteristics of plastic particles ingested by seabirds. Mar. Environ. Res. 23, 175-206. 
Ryan, P.G., 2008. Seabirds indicate changes in the composition of plastic litter in the Atlantic and south-western Indian Oceans. Mar. Pollut. Bull. 56, 1406-1409.

Ryan, P.G., 2016. Ingestion of plastics by marine organisms. Springer, Berlin, Heidelberg, pp. 1-32.

Ryan, P.G., Moore, C.J., van Franeker, J.A., Moloney, C.L., 2009. Monitoring the abundance of plastic debris in the marine environment. Philos. Trans. Royal Soc. B. 364, 1999-2012. Shaw, D.G., Day, R.H., 1994. Colour- and form-dependent loss of plastic micro-debris from the North Pacific Ocean. Mar. Pollut. Bull. 28, 39-43.

Sileo, L., Sievert, P.R., Samuel, M.D., Fefer, S.I., 1990. Prevalence and characteristics of plastic ingested by Hawaiian seabirds, in: Shomura, R.S., Godfrey, M.L. (Eds.). U.S.

Department of Commerce, Honolulu, Hawaii.

Spear, L.B., Ainley, D.G., Ribic, C.A., 1995. Incidence of plastic in seabirds from the tropical Pacific, 1984-1991: relation with distribution of species, sex, age, season, year, and body weight. Mar. Environ. Res. 40, 123-146.

Tanaka, K., Takada, H., Yamashita, R., Mizukawa, K., Fukuwaka, M., Watanuki, Y., 2015. Facilitated leaching of additive-derived PBDEs from plastic by seabirds' stomach oil and accumulation in tissues. Environ. Sci. Technol. Lett. 49, 11799-11807.

Thiel, M., Hinojosa, I.A., Miranda, L., Pantoja, J.F., Rivadeneira, M.M., Vásquez, N., 2013. Anthropogenic marine debris in the coastal environment: a multi-year comparison between coastal waters and local shores. Mar. Pollut. Bull. 71, 307-316.

UNEP, 2014. Valuing plastics: The business case for measuring, managing and disclosing plastic use in the consumer goods industry. United Nations Environment Programme, Kenya. van Franeker, J.A., Blaize, C., Danielsen, J., Fairclough, K., Gollan, J., Guse, N., Hansen, P.L., Heubeck, M., Jensen, J.K., Le Guillou, G., Olsen, B., Olsen, K.O., Pedersen, J., Stienen, E.W., Turner, D.M., 2011. Monitoring plastic ingestion by the Northern Fulmar Fulmarus glacialis in the North Sea. Environ. Pollut. 159, 2609-2615.

van Franeker, J.A., Law, K.L., 2015. Seabirds, gyres and global trends in plastic pollution. Environ. Pollut. 203, 89-96.

van Franeker, J.A., Meijboom, A., 2002. Marine litter monitoring by Northern Fulmars (a pilot study), Wageningen, Alterra, pp. 1-72.

Verlis, K.M., Campbell, M.L., Wilson, S.P., 2013. Ingestion of marine debris plastic by the Wedge-tailed Shearwater Ardenna pacifica in the Great Barrier Reef, Australia. Mar. Pollut. Bull. 72, 244-249.

Vlietstra, L.S., Parga, J.A., 2002. Long-term changes in the type, but not amount, of ingested plastic particles in Short-tailed Shearwaters in the southeastern Bering Sea. Mar. Pollut. Bull. 44, 945-955.

Whittow, C.G., 1997. Wedge-tailed Shearwater (Puffinus pacificus), in: Poole, A. (Ed.), Birds of North America Online No. 305. Cornell Lab of Ornithology, Ithaca, NY. 
Table 1

Summary of plastic ingestion studies for fledgling Wedge-tailed Shearwaters. FO: Frequency of occurrence (\%).

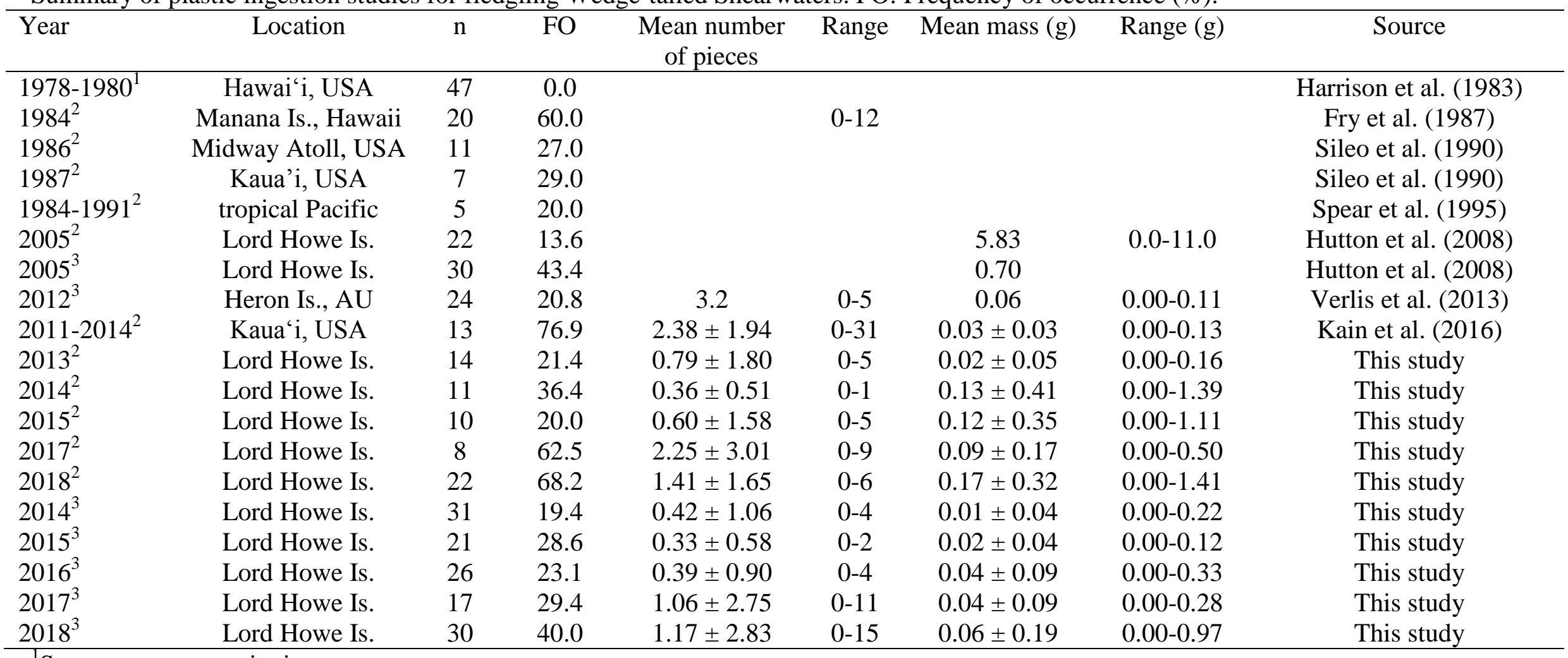

${ }^{1}$ Spontaneous regurgitations.

${ }^{2}$ Necropsy of freshly deceased fledglings (proventriculus and gizzard).

${ }^{3}$ Live fledglings sampled using stomach flushing (lavage; proventriculus only). 
Table 2

Colour of ingested plastic from Wedge-tailed Shearwater fledglings, reported as the number of items (proportion).

\begin{tabular}{lccccccccc}
\hline Year & Location & $\mathrm{n}$ & White & Blue & Green & Red & Yellow & Black & Source \\
\hline 2005 & Lord Howe Is. & 30 & $57(80.3)$ & $2(2.8)$ & $10(14.1)$ & 0 & $2(2.8)$ & 0 & Hutton et al. (2008) \\
2012 & Heron Is., AU & 24 & $9(37.5)$ & 0 & $8(31.3)$ & $2(6.3)$ & $2(12.3)$ & $3(12.5)$ & Verlis et al. (2013) \\
$2011-2014$ & Kaua'i, USA & 30 & $24(77.4)$ & 0 & $2(6.5)$ & $1(3.2)$ & $2(6.5)$ & $2(6.5)$ & Kain et al. (2016) \\
2013 & Lord Howe Is. & 14 & $4(36.4)$ & 0 & $2(18.2)$ & 0 & 0 & $5(45.5)$ & This study \\
2014 & Lord Howe Is. & 42 & $10(58.8)$ & $1(5.9)$ & $4(23.5)$ & 0 & $1(5.9)$ & $1(5.9)$ & This study \\
2015 & Lord Howe Is. & 31 & $8(61.5)$ & 0 & $3(23.1)$ & $1(7.7)$ & 0 & $1(7.7)$ & This study \\
2016 & Lord Howe Is. & 27 & $5(50.0)$ & 0 & $1(10.0)$ & $3(30.0)$ & 0 & $1(10.0)$ & This study \\
2017 & Lord Howe Is. & 29 & $30(76.9)$ & $5(12.8)$ & $1(2.6)$ & 0 & $1(2.6)$ & $2(5.1)$ & This study \\
2018 & Lord Howe Is. & 52 & $169(75.4)$ & $9(4.0)$ & $27(12.1)$ & $4(1.8)$ & $4(1.8)$ & $11(5.0)$ & This study \\
\hline
\end{tabular}


Table 3

Jaccard's index of similarity for the colour of plastics ingested by Wedge-tailed Shearwaters fledglings on Lord Howe Island, Australia, from 2013-2018. Values of $\mathrm{J}=0$ indicate complete dissimilarity, and $\mathrm{J}=1$ indicate identical colour composition. Values of $\mathrm{J}<0.60$ are significant.

\begin{tabular}{ccccccc}
\hline Year & 2005 & 2013 & 2014 & 2015 & 2016 & 2017 \\
\hline 2013 & 0.34 & & & & & \\
2014 & 0.65 & 0.43 & & & & \\
2015 & 0.61 & 0.45 & 0.78 & & & \\
2016 & 0.43 & 0.39 & 0.49 & 0.60 & & \\
2017 & 0.74 & 0.28 & 0.60 & 0.53 & 0.41 & \\
2018 & 0.85 & 0.36 & 0.69 & 0.67 & 0.50 & 0.80 \\
\hline
\end{tabular}


Table 4

Jaccard's index of similarity for the type of plastics ingested by Wedge-tailed Shearwaters fledglings on Lord Howe Island, Australia, from 2013-2018. Values of $\mathrm{J}=0$ indicate complete dissimilarity, and $\mathrm{J}=1$ indicate identical type composition. Values of $\mathrm{J}<0.60$ are significant.

\begin{tabular}{cccccccc}
\hline Year & 2005 & 2013 & 2014 & 2015 & 2016 & 2017 & 2018 \\
\hline 2013 & 0.47 & & & & & & \\
2014 & 0.56 & 0.77 & & & & & \\
2015 & 0.64 & 0.55 & 0.73 & & & & \\
2016 & 0.82 & 0.58 & 0.67 & 0.73 & & & \\
2017 & 0.84 & 0.55 & 0.68 & 0.77 & 0.95 & & \\
2018 & 0.94 & 0.50 & 0.58 & 0.67 & 0.87 & 0.87 & 0.94 \\
\hline
\end{tabular}




\section{Table 5}

Wedge-tailed Shearwater fledglings sampled on Lord Howe Island during 2005-2018. Number of live birds (lavage) and freshly deceased birds (necropsy). Plastic is reported by type (total number ingested and proportion (\%)) following categories outlined by van Franeker and Law (2015): industrial pellets and user plastic (all non-industrial remains of plastic objects) which are differentiated into five subcategories (see text).

\begin{tabular}{cccccccccc}
\hline Year & Necropsy & Lavage & $\begin{array}{c}\text { Prevalence } \\
(\%)\end{array}$ & Industrial & \multicolumn{5}{c}{ User } \\
\hline 2005 & 0 & 30 & 43.3 & 0 & 0 & 0 & 0 & $70(98.6)$ & $1(1.4)$ \\
2013 & 14 & 0 & 21.4 & $4(36.4)$ & 0 & 0 & 0 & $7(63.6)$ & 0 \\
2014 & 11 & 31 & 23.8 & $4(23.5)$ & 0 & 0 & 0 & $12(70.6)$ & $1(5.9)$ \\
2015 & 10 & 21 & 25.8 & $1(7.7)$ & 0 & 0 & 0 & $10(76.9)$ & $2(15.4)$ \\
2016 & 1 & 26 & 33.3 & $1(10.0)$ & 0 & 0 & 0 & $9(90.0)$ & 0 \\
2017 & 12 & 17 & 32.0 & $3(7.7)$ & 0 & 0 & 0 & $35(89.7)$ & $1(2.6)$ \\
2018 & 22 & 30 & 51.9 & $2(3.1)$ & 0 & 0 & 0 & $63(96.9)$ & 0 \\
\hline
\end{tabular}

*Items in the other category included pink, white, and purple balloons (Fig. 2) and melted plastic. 
Fig. 1. Sampling sites for Wedge-tailed Shearwater (Ardenna pacifica) fledglings on Lord Howe Island during 2005 and 2013-2018.

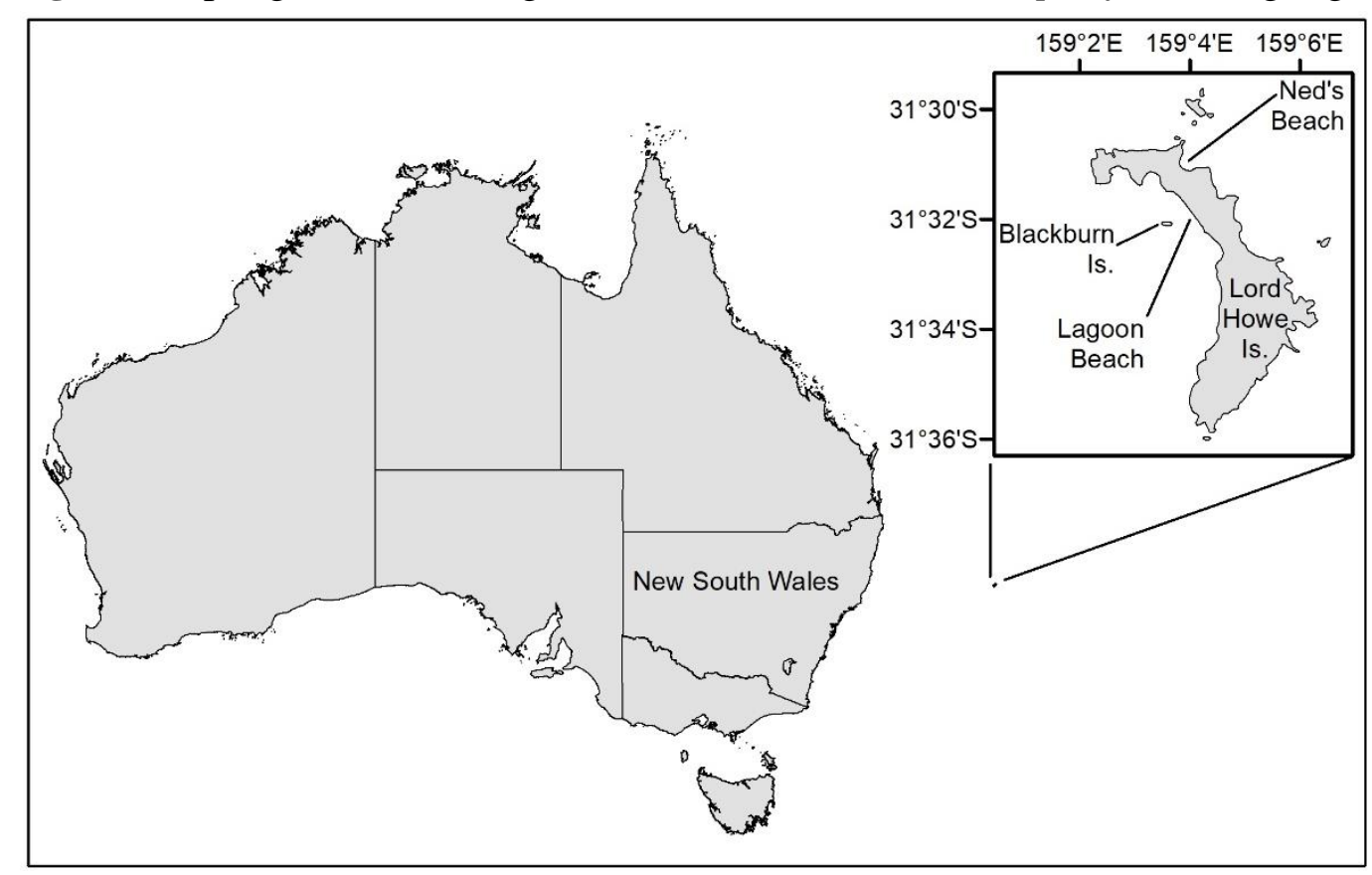


Fig. 2. Ingested debris recovered from fledgling Wedge-tailed Shearwaters on Lord Howe Island: (A) purple balloon removed from the gizzard (a second white balloon lodged in the esophagus is not visible in the photo), (B) fragments of hard plastic, including two industrial pellets (nurdles) and part of a cylum glow stick, from eight individual birds.

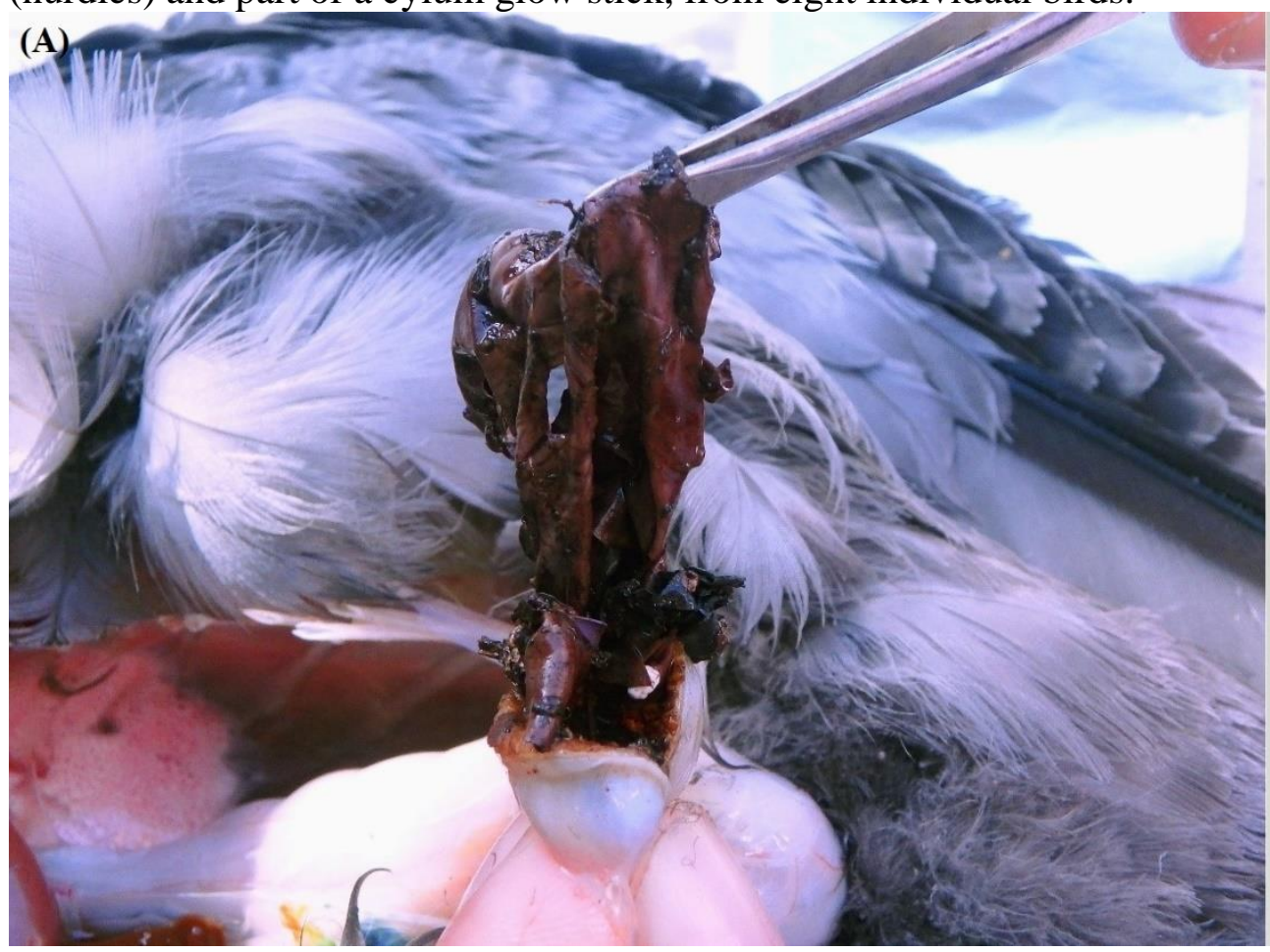

(B)
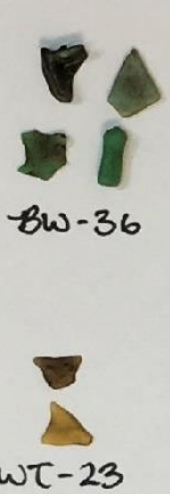

$-8 \omega-2 c$

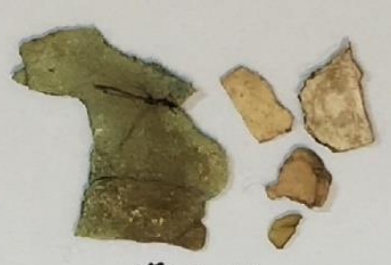

$B w-11$

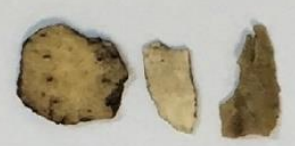

$\omega \tau-2 q$

$-8 w-19$

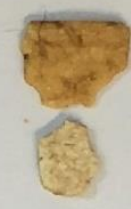

$\omega \tau-32$

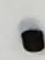

$\stackrel{\mathrm{cm}}{ }$

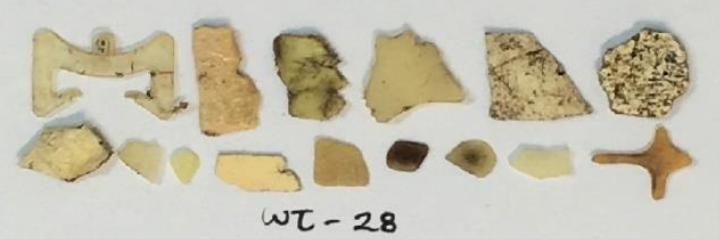

